\title{
Age-related macular degeneration: current knowledge of zinc metalloproteinases involvement
}

Francesca Liva, ${ }^{1, \#}$ Doretta Cuffaro, ${ }^{1,2,{ }^{*}}$ Elisa Nuti, ${ }^{1}$ Susanna Nencetti, ${ }^{1}$ Elisabetta Orlandini, ${ }^{2,3}$ Giovanni Vozzi ${ }^{2}$ and Armando Rossello ${ }^{1,2, *}$

${ }^{1}$ Department of Pharmacy, University of Pisa, Via Bonanno 6, 56126 Pisa, Italy; ${ }^{2}$ Research Center "E. Piagio," University of Pisa, Pisa, 56122, Italy; ${ }^{3}$ Department of Earth Sciences, University of Pisa, Via Santa Maria 53, 56126 Pisa, Italy

Corresponding author

* Prof. Armando Rossello, Department of Pharmacy, Via Bonanno 6, 56126 Pisa, Italy e-mail: armando.rossello@farm.unipi.it

\# These authors contributed equally in this work.

\begin{abstract}
:
Background: Advanced age-related macular degeneration (AMD) is the leading cause of blindness in the elderly with limited therapeutic options. The disease is characterized by photoreceptor loss in the macula and reduced retinal pigment epithelium (RPE) function, associated with matrix degradation, cell proliferation, neovascularization and inflammation. Matrix metalloproteinases (MMPs), a disintegrin and metalloproteinases (ADAMs) and a disintegrin and metalloproteinase with thrombospondin motifs (ADAMTSs) play a critical role in the physiology of extracellular membrane (ECM) turnover and, in turn, in ECM pathologies, such as AMD. A balance between the activities of MMPs and Tissue inhibitors of metalloproteinase (TIMPs) is crucial for the integrity of the ECM components; indeed, a dysregulation in the ratio of these factors produces profound changes in the ECM, including thickening and deposit formation, which eventually might lead to AMD development.

Objective: This article reviews the relevance and impact of zinc metalloproteinases on the development of AMD and their roles as biomarkers and/or therapeutic targets. We illustrate some studies on several inhibitors of MMPs currently used to dissect physiological properties of MMPs. Moreover, all molecules or technologies used to control MMP and ADAM activity in AMD are analyzed.

Conclusions: This study underlines the changes in the activity of MMPs expressed by RPE cells, highlights the functions of already used MMPs inhibitors and consequently suggests their application as therapeutic agents for the treatment of AMD.
\end{abstract}


Keywords: AMD, RPE, MMPs, ADAMs, ADAMTSs, MMP Inhibitors

\section{Introduction}

Age-related macular degeneration (AMD) is a multifactorial disorder influenced by interaction between genetic and environmental risk factors. AMD is characterized by a pathological extracellular matrix (ECM) remodeling and by deposition of lipids or lipoproteins within the Bruch's membrane (BrM) in the retinal area [1]. Bruch's membrane is a penta laminated extracellular matrix responsible for the diffusion between the retinal pigment epithelium (RPE) and the choroidal vasculature. The aging process causes a progressive thickening of this membrane due to the deposition of matrix components and the consequence is a decreased efficiency of the hydraulic conductivity of BrM [2].

A large number of proteases are responsible for the proteolytic processes in the BrM. The main enzymatic group involved in the degradation of ECM is the superfamily of the zinc metalloproteinases, which includes the matrix metalloproteinases (MMPs), also known as matrixins, the A Disintegrin and Metalloproteinase Domain (ADAMs) and the A Disintegrin And Metalloproteinase with Thrombospondin motifs (ADAMTSs) [3].

\subsection{What is AMD?}

AMD is the most common cause of irreversible blindness in people aged 50 and over in the developed world [4, 5]. It occurs when the small central portion of the retina, known as the macula, deteriorates causing a progressive visual impairment due to the neurodegeneration at the level of photoreceptors/retinal pigment epithelial complex. In particular, the pathological area involved in AMD is represented by photoreceptors, the retinal pigment epithelium (RPE), the Bruch's membrane (BrM), and the choriocapillaris. So far, there is no treatment for this pathology, and for this reason, the identification of risk factors is a significant point to provide cause and possible intervention strategies. Unfortunately, nowadays the understanding of biological nature, risk factors and disease therapies remains limited [6].

Epidemiological studies have shown that genetic predisposition, and other several risk factors (modifiable and non-modifiable) such as smoking, obesity, age, gender, hypertension, hyperlipidemia, cardiovascular disease and nutritional deficiencies are associated with the development of AMD (Table 1). 
Table 1. Risk Factors for Age-Related Macular Degeneration.

\begin{tabular}{|c|c|c|c|}
\hline Risk Factors & First Author & Publication year & References \\
\hline Genetic factors & Fritsche L.G. & 2016 & {$[6]$} \\
\hline Hypertension & Vingerling J.R. & 1995 & {$[7]$} \\
\hline $\begin{array}{c}\text { Low dietary intake } \\
\text { of antioxidants }\end{array}$ & Seddon J.M. & 1994 & {$[8]$} \\
\hline Age $>65$ years & Friedman D.S. & 2004 & {$[9]$} \\
\hline $\begin{array}{c}\text { White race } \\
\text { A history of } \\
\text { past 20 years }\end{array}$ & McCarty C.A. & 2008 & {$[10]$} \\
\hline $\begin{array}{c}\text { Cbesity (BMI }>30 \\
\text { Kg/m2) }\end{array}$ & Rowan S. & 2013 & {$[11]$,} \\
\hline $\begin{array}{c}\text { Gender (female) } \\
\text { Mcho }\end{array}$ & Armstrong R.A. & 2015 & {$[13]$} \\
\hline
\end{tabular}

Age is the most important risk factor identified to date. In fact, AMD is rare in people younger than 50 years, and its frequency of development increases considerably after 75 years of age [15].

Moreover, a family history of AMD confers an established risk factor, which is typically multifactorial in nature. Different studies [16] have identified polymorphism in genes that encode complement factors, important immunosystem elements, as a positive or negative influencer for AMD risk. In fact, the development of AMD includes mutations in the complement gene $\mathrm{H}(\mathrm{CFH})$ [17] and, in contrast, other studies showed protective effects of genetic polymorphism in complement component 2 (C2) and complement factor B (CFB) [18]. In particular, $\mathrm{CFH}$ acts as a complement inhibitor and it is believed that a polymorphism of this gene reduces its ability to downregulate complement activity. This allows continuous inflammation and pathogenic degeneration of the macula [19]. Therefore, the genetic defects of proteins may play a fundamental role in development of AMD by disrupting the homeostatic balance between pro and anti-inflammatory molecules generated by RPE cells after exposure to 
inflammatory stimuli [20], either locally-generated or transmissible by blood. In addition to the role played by genetic polymorphisms, environmental factors also contribute to the development of AMD.

\subsection{Pathophysiology and Classification: Wet and Dry AMD}

In general, the most relevant pathogenic mechanisms responsible for AMD development are: the accumulation of a cellular debris, hypoxia, local inflammation, and neovascularization. Among them, the accumulation of extracellular matrix and polymorphous material, "drusen", in the macula is the hallmark of AMD.

Human retinal pigment epithelium (RPE) is the structure in the retina responsible for the maintenance of photoreceptor cells, and the death of photoreceptor seems to be strictly connected with a RPE degeneration due to drusen accumulation. Typically, drusen are spread out between RPE basement and the inner collagenous area of Bruch's membrane (Figure 1) [21]. An inefficient disposal of the accumulated ECM molecules by RPE or a dysregulation of inflammatory mediators may be the hypothesized mechanisms for drusen accumulation [22].

\section{Category}

1

2

3

4

\section{Clinical signs}

$$
\begin{aligned}
& \text { None or a few small } \\
& \text { drusen }(<63 \mu \mathrm{m})
\end{aligned}
$$

Multiple small drusen, few intermediate drusen (63-124 $\mu \mathrm{m})$ or RPE abnormalities

Extensive intermediate drusen, at least one large $(125 \mu \mathrm{m})$ drusen, or GA not involving the foveal center

\section{GA involving the fovea or/and any of the feature of wet AMD}

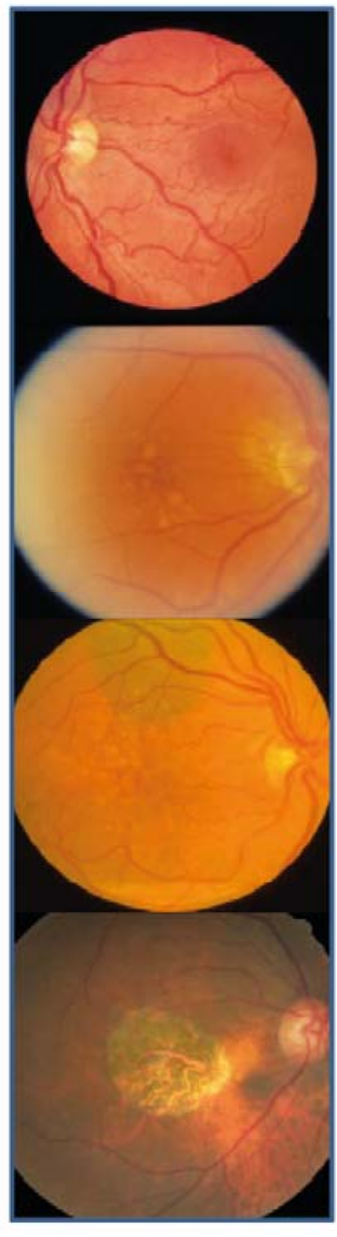

NO AMD

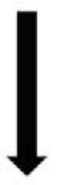

Early AMD

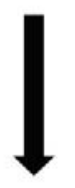

Intermediate AMD

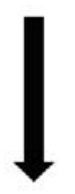

Advanced AMD 
Figure 1. Classification of AMD, according to Age-Related Eye Disease Study. $\mathrm{GA}=$ Geographic atrophy. [Copyright: Figure 1.1 This image was originally published in the Retina Image Bank $\mathbb{}$ website. H. Michael Lambert, MD. Normal Retina. Retina Image Bank. 2014; Image Number 16035. (C) the American Society of Retina Specialists. Figure 1.2 This image was originally published in the Retina Image Bank ${ }^{\circledR}$ website. H. Michael Lambert, MD. Dry AMD. Retina Image Bank. 2013; Image Number 8688. (C) the American Society of Retina Specialists. Figure 1.3:This image was originally published in the Retina Image Bank ${ }^{\circledR}$ website. Jerald A. Bovino, MD. Dry Macular Degeneration. Retina Image Bank. 2013; Image Number 6379. (C) the American Society of Retina Specialists. Figure 1.4: This image was originally published in the Retina Image Bank ${ }^{\circledR}$ website. Young Hee Yoon, MD, PhD. Geographic Atrophy. Retina Image Bank. 2012; Image Number 530. (C) the American Society of Retina Specialists.]

AMD may progress from early signs (early AMD), to its intermediate and advanced forms [23]. While early stages of the disease are mostly asymptomatic, the late stages cause severe vision loss due to disruption of the retinal anatomy and ultimately photoreceptor degeneration. AMD is classified as intermediate AMD, the so called "Dry form" (geographic atrophy, GA, when angiogenesis is absent), and advanced AMD, the so called "Wet form" (choroidal neovascularization, $\mathrm{CNV}$, accompanied by angiogenesis) [24]. AMD classification was made by the Age-related Eye Disease Study (AREDS) and it is based on drusen, atrophy and neovascularization (Figure 1): a situation of "no AMD" is characterized by none or a few small drusen $(<63 \mu \mathrm{m})$, Intermediate AMD (Dry) is defined by extensive intermediated-size drusen (63-124 $\mu \mathrm{m})$ or GA not involving foveal center, Advanced AMD (Wet) is determined by GA and CNV [25].

Dry AMD is the most frequent and less dangerous form of disease. It represents 85 to $90 \%$ of cases and its course is usually slow and degenerative. In the dry type of $\mathrm{AMD}$, the deterioration of the retina is associated with the development of drusen, microcalcifications and irregular dystrophy with distorted and blurred vision at first, followed by a loss of central vision (Figure 1) [26]. This phenomenon leads to a thinning and drying out of the macula, causing loss of macula functionality. Dry AMD is also called non-neovascular AMD and non-exudative AMD because it does not involve the leakage of fluids from blood vessels. Advanced cases - "late dry" AMD are called geographic atrophy (GA) because large sections of the retina that are well demarcated (geographies), stop functioning. GA is characterized by the gradual expansion of atrophic macular changes, which results in a degeneration of vision abilities [27].

The wet/neovascular type affects approximately $10-15 \%$ of individuals with AMD, but accounts for approximately $90 \%$ of all cases of severe vision loss from the disease. Wet AMD is a condition characterized by choroidal neovascularization or CNV [28] where new pathogenic blood vessels grow in the choroid layer breaching the BrM and going across the sub-retinal space. Since these new blood vessels are abnormal, they tend to break, bleed, and leak fluid, damaging the macula that lifts up and pulls away from its base. The leaking gets into the layers of the retina - including the layers of the macula - and can cause scar tissue to form and retinal cells to stop functioning. 


\subsection{Bruch's membrane and RPE involvement}

Bruch's membrane $(\mathrm{BrM})$ is a thin $(2-4 \mu \mathrm{m})$, acellular, extracellular matrix located between the retina and choroid and consists of five layers: the basement membrane of the RPE, the inner collagenous layer, a central band of the elastic fiber, the outer collagenous zone, and the choriocapillaris endothelium basement membrane (Figure 2). 


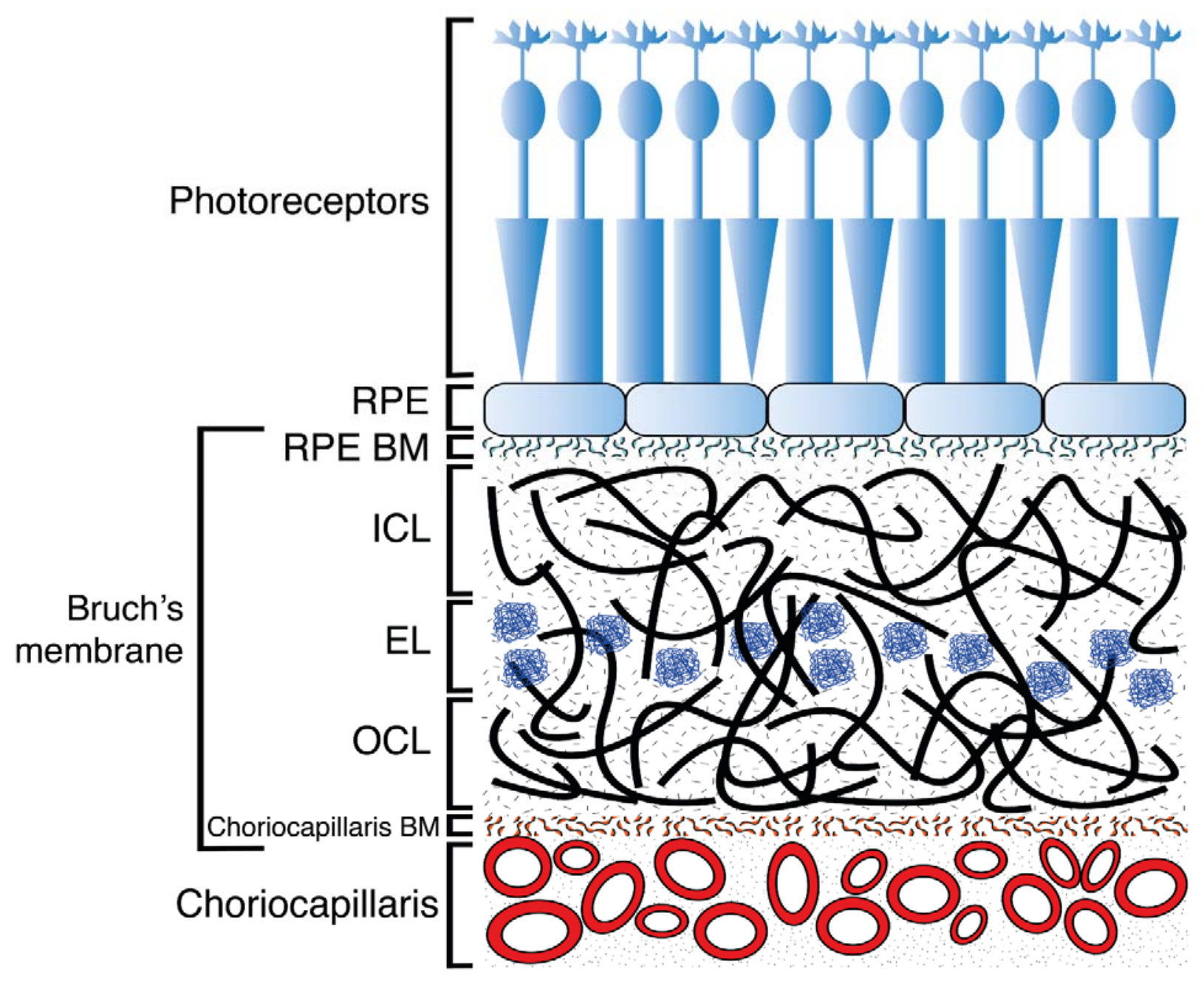

Figure 2. The composition of human extracellular matrix in retinal area. RPE BM= Retinal Pigment Epithelium Basal Membrane, composed by Coll IV, V, laminins, E/N -1,-2, PGs (mainly HSPGs), fibulins; ICL= Inner Collagene Layer, composed by Coll I, III, V, fibronectin, HSPGs, fibulins; $\mathrm{EL}=$ Elastin layer, composed by elastin, coll VI, bronectin, HSPGs, fibulins; $\mathrm{OCL}=$ Outer Collagene Layer, composed by Coll I, III, V, fibronectin, HSPGs, fibulins; Choriocapillaris BM= Choriocapillaris Basal Membrane, composed by Coll IV, V, VI (XV, XVIII*), laminins, E/N -1,-2, PGs (mainly HSPGs), fibulins; E/N= entactin/nidogen; $\mathrm{PGs}=$ proteoglycans; $\mathrm{HSPGs}=$ heparin sulphate proteoglycans.

In physiological conditions, BrM is a physical barrier permeable to fluids and small molecules, it serves as a selective conduit for nutrients transported from the choroidal vasculature to the retina and for metabolic wastes transported from the retina to the circulation [29]. Moreover, it gives a structural support against 
neovascularization i.e. the invasion of new vessels into the retina. In fact, containing the anti-angiogenic molecules in the elastin layer it prevents the growth of neovascular capillaries from the choroid, separating the vascular choroid from the avascular outer retina.

Several recent findings support the involvement of BrM in AMD development [30]. Studies of hydraulic conductivity have invariably shown that the BrM permeability decreases with ageing [31]. Over the course of time, $\mathrm{BrM}$ tends to accumulate debris in the elastin layer (EL) and also drusen between the inner collagen layer (ICL) and RPE basal lamina (RPE-BL). This debris accumulation causes a reduction of the permeability and a thickening of BrM elastic layer [32]. The resulting porous BrM elastic layer becomes a feeble structure and may trigger the development of neovascularization [33].

RPE is constituted by a thin layer of cuboidal cells close to photoreceptor cells. The relationship between photoreceptors and RPE cells is fundamental for the correct function of sight. In fact, the dysregulation of RPE cells is responsible for photoreceptors death and for a consequent degeneration of the visual ability causing retinal pathologies such as AMD [34]. In particular, RPE plays a central role in the development and maintenance of adjacent photoreceptors in the vertebrate retina as well as in retinal physiology by forming the outer blood-retinal barrier. RPE cells regulate the production of various matrix proteins (collagen type I, collagen type IV, and laminin) but also BrM structural elements thus suggesting to be the site of the primary lesion in AMD [35].

Several authors have shown that human RPE in cell culture releases several members of the family of matrix metalloproteinases (MMPs), and the tissue inhibitor of metalloproteinases (TIMPs) (see next paragraph) [36,37]. Modulation of ECM turnover by changing RPE secretion of these matrix metalloproteinases and their TIMPs may play a central role in the normal functions and in the pathologies of the retina. The secretions of RPE could be altered in the retinal interphotoreceptor matrix (IPM), as well as in the BrM. The fraction associated with RPEIPM may manifest interferences with the metabolism of retina as a whole, leading indirectly to stimulation of RPE, and causing the development of AMD. Nowadays, the regulation of RPE cellular functions is not completely understood and it is still under investigation.

\subsection{Emerging drug treatments for Dry and Wet AMD}

Although in the last years many research efforts have been directed toward understanding the pathophysiology of the disease in order to develop new therapies, none of the current treatments can cure the disease or reverse its course. In general, Dry and Wet AMD require different treatments due to the different main pathological manifestations, GA and CNV.

Dry AMD: The most promising therapeutic agent for treating Dry AMD is the human monoclonal antibody Lampalizumab, discovered by the 18-month Phase II MAHALO study. The intravitreal administration of this molecule, which is a selective complement factor D inhibitor, was associated with a significant decrease (44\%) in the GA progression. Lampalizumab reached Phase III in the Chroma and Spectri clinical trials, so far the largest 
studies on GA, but results published at the end of 2018 demostrated that it could not reduce GA enlargement during 48 weeks of treatment. [38,39].

Another clinical trial (TOGA) demonstrated the efficacy of tetracyclines. In particular, a low-dose administration of Doxycycline, a broad-spectrum antibiotic, could slow the progression of GA in patients with AMD [40].

A topical ophthalmological drug under development is MTP-131 (Ocuvia), a mitochondrial protective compound really effective in several experimental models and currently under clinical trial in order to evaluate the tolerability in AMD patients [41,42].

Wet AMD: the treatment of wet AMD focused on the development of CNV that is mainly due to VEGF activation [43]. Pegatinib is the first anti-VEGF approved drug and it is a specific RNA aptamer able to bind the VEGF-165 isoform. Its efficacy was demonstrated in the clinical trial VISION based on intravitreal administration and it was the starting point to develop more effective anti-VEGF treatments. Successively, the recombinant humanized IgG1 monoclonal antibodies were largely studied and analyzed, reporting a strong anti-VEGF-A activity: Ranibizumab, Bevacizumab [44] and the most recent Afibercept [45], which is a VEGF-A receptor decoy. Recently, these antiVEGF agents were shown to be highly effective by intravitreal administration but they are no suitable for a long lasting therapy. An innovative drug is Pegpleranib which is a platelet-derived grown factor inhibitor, promoting the pericyte density in the neovascular membrane, making it more receptive to anti-VEGF agents. The Phase III program of Pegpleranib consists of evaluating its efficacy and tolerability in combination with the anti-VEGF agents (Ranizumab, Bevacizumab and Aflibercept)[46,47]. Unfortunately, at the end of 2016 Ophthotech Corporation announced that the co-adinistration of Pegpleranib with Ranizumab did not result in a major benefit compared to Ranizumab monotherapy for AMD treatment as measured by the mean change in visual activity at the 12 month time point.

\section{Matrix Metalloproteinases (MMPs), A Disintegrin and Metalloproteinase Domain (ADAMs) and A Disintegrin And Metalloproteinase with Thrombospondin motifs (ADAMTSs): a role in AMD}

The extracellular matrix is involved in the physiological processes of tissue architecture characterized by a natural balance between synthesis and degradation of ECM constituents. The continuous rebuilding of connective tissue in pathological and physiological processes is due to specific endopeptidases, the zinc metalloproteinases, which include the superfamily of the metzincins zinc-dependent endopeptidases. Metzincins are able to cleave proteins of the extracellular matrix participating both to unspecific protein degradation and to specific cleavage events, such as enzyme activation. It is evident that the deregulation of their degrading potential can lead to various serious pathologies. Based on sequence and structural similarities, metzincins are classified in four distinct subfamilies: the astacins, the matrixins (matrix metalloproteinases, MMPs), the serralysins (large bacterial proteinases) and the adamalysins (ADAMs and ADAMTSs) (Figure 3). 


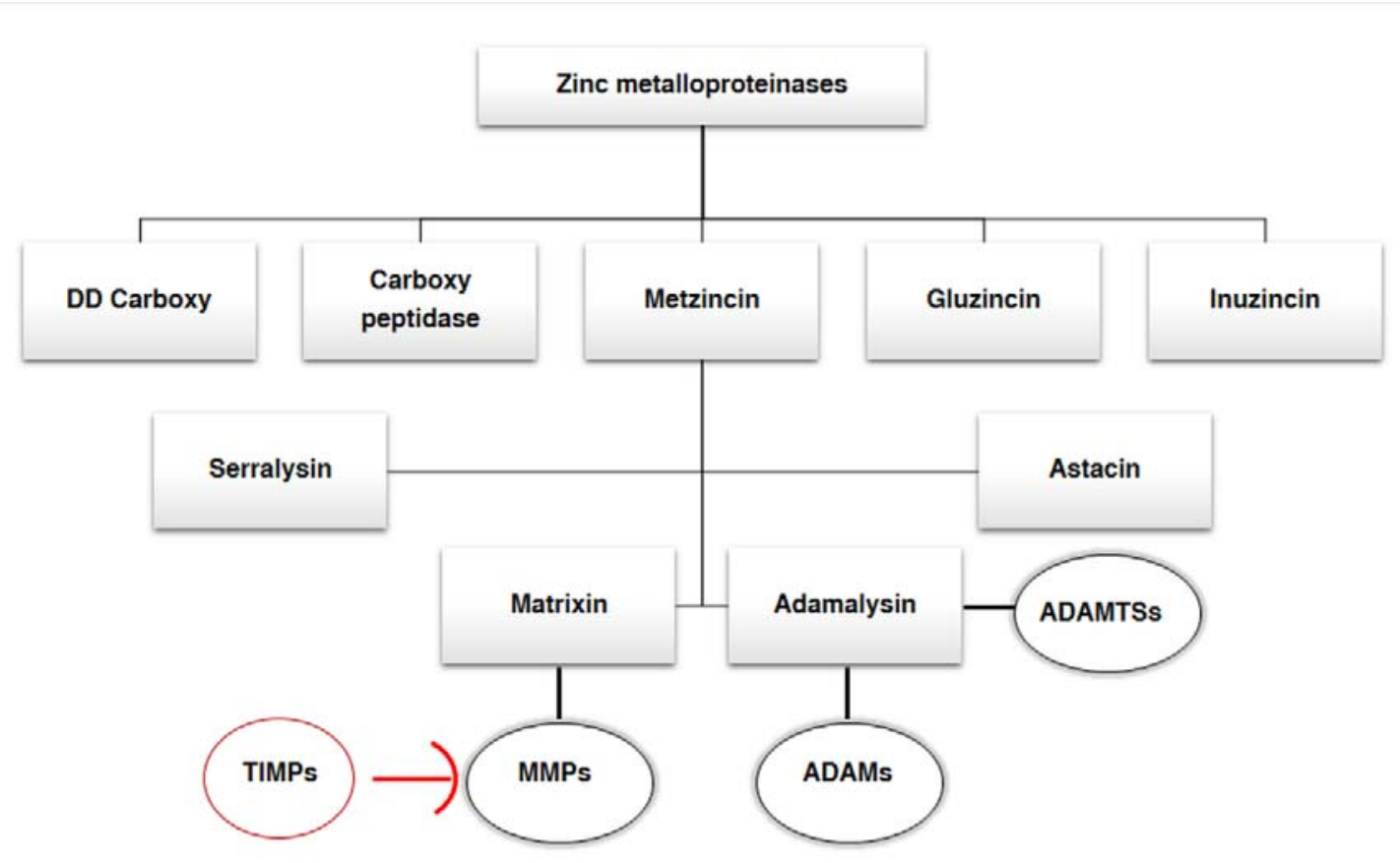

Figure 3. Schematic representation of Metzincins classification.

In this chapter the role of Metzincins in AMD disease is analyzed, considering that MMPs, ADAMs and ADAMTSs play an important role in extracellular matrix (ECM) turnover. MMPs are essential for maintaining ocular physiology and their inordinate activities have been linked to several neurodegenerative disorders of the retina, including age-related macular degeneration. Expression of most MMPs in ocular tissues, under normal conditions, is low and it is induced when remodeling of ECM is required.

\subsection{MMPs}

Matrix Metalloproteinases (MMPs), or Matrixins, constitute a family of more than twenty zinc-dependent endopeptidases homogeneous for structure, function and localization. The widely used classification of MMPs is based on substrate specificity, sequence similarity, domain organization. They are divided in five main groups:

- Collagenases (MMP-1, MMP-8, MMP-13 and MMP-18) that cleave interstitial collagens I, II, III and a various number of ECM and no-ECM molecules.

- Gelatinases (MMP-2 Gelatinase A and MMP-9 Gelatinase B) that digest type IV collagen and gelatin, and are discriminated by the presence of gelatin-binding region inside the catalytic domain.

- Stromelysins (MMP-3 and MMP-10) that display a broad ability to digest ECM proteins but are unable to cleave the triple helical fibrillar collage.

- Matrylisins (MMP-7 and MMP-26) that are characterized by the lack of the hemopexin domain.

- Membrane-Type MMPs (MT-MMPs) that are divided in type I (MMP-14, MMP-15, MMP-16 and MMP24) and the glycosylphosphatidylinositol (GPI)-anchored proteins MT5-, and MT6-MMP (MMP17 and MMP-25). All MT-MMPs have a furin cleavage site in the propeptide and they are all capable of activating 
other proteins. In particular MT1-MMP has a collagenolytic activity on type I, II, and III collagen and other components of ECM

- Other MMPs (MMP-11, MMP-12, MMP-19, MMP-20, MMP-22, MMP-23, and MMP-28) that are not classified in the above categories.

MMPs activity is strictly regulated by various factors but in particular by their tissue inhibitors, TIMPs (Tissue inhibitors of Metalloproteinases). The complexes MMPs-TIMPs are responsible for the balance in the regulation of numerous cascade of enzymatic reactions involved in many physiological processes.

The turnover of matrix in the retina bordering the apical interphotoreceptor matrix (IPM) and the basolateral aspect of RPE cells (Bruch's membrane) is thought to be mediated by metalloproteinases and their related inhibitors (TIMPs).

From a structural point of view the family of MMPs mostly shares a common three domain-based structure that consists of:

- a signal sequence responsible for the detection of the molecules and the consequent MMP secretion

- a pro-peptide domain at the amino terminal, which is removed for MMP activation.

- a catalytic domain that contains a zinc ion essential for the proteolytic activity.

- a hemopexin domain at the carboxylic-terminal, that has a functional role in substrate binding and interactions.

\subsubsection{MMPs in the eye}

Recent studies using eye tissues or cell culture systems suggest that MMPs and their inhibitors play a key role in the homeostasis of extracellular matrix in the eye. A balance between the activities of MMPs is significant to the remodeling of the ECM components, including collagen, vitronectin, fibronectin, laminin, elastin and proteoglycans. A small dysregulation in the ratio of these factors can produce profound changes in the retinal ECM, including thickening and deposit formation [48]. Nowadays, the exact sources of MMPs in the retinal area are still unknown even if they are mainly released by BrM and RPE cells [49].

In general, MMPs level increases in the BrM proportionally with the BrM thickness with age. After the release from plasma or from RPE or choroidal cells, MMPs can diffuse across BrM following a molecular weight exclusion limit. In fact, only those MMPs with a small molecular weight, such as MMP-1, MMP-2 and MMP-3, can diffuse. Nevertheless, analyzing another potential pathway MMPs may be passively incorporated into the $\mathrm{ECM}$ of BrM if their release is coincident with the synthesis of BrM components. In this case, even MMPs with high molecular weight such as MMP-9 could be incorporated [50].

The presence of some MMPs and TIMPs in RPE cells is well known [51, 21]. MMP-1 (interstitial collagenase), MMP-2 (gelatinase A), MMP-3 (stromelysin-1), MMP-9 (gelatinase B) and MT1-MMP but also TIMPs 1 and 3 are present in human IPM and vitreous and they are the most reported. Eichler et al. [52] and Li et al. [49] demonstrated that MMP-1, $-2,-3$, and -9 were expressed in cultured RPE cells. Moreover, Platner et al. [53], 
showed a highly significant increase in the level of gelatinase A in RPE-associated Interphotoreceptor matrix (IPM) in AMD compared to normal donors, therefore suggesting a role for gelatinase $\mathrm{A}$ in the pathology of AMD.

Not only MMPs are responsible for the accumulation or the degradation of ECM components in BrM but also TIMPs have a role. In particular, the age-related increased level of TIMP-3 is connected with a decreased level of ECM components in BrM [54]. In fact, the TIMP-3 growth is somehow counterbalanced by an age dependent production of proMMP-2 and -9 [55], that remain in the deactivate form.

A dysfunction of RPE cells activity causes alterations in MMPs/TIMPs balance and it is responsible for an mutated activity of MMPs [35]. Alteration in the expression and activity of MMPs expressed by RPE, has been associated with pathologies involving matrix degradation, cell proliferation, neovascularization and inflammation and cell adhesion in vitreo-retinal disorders, such as Choroidal neovascularization (CNV) and Proliferative vitreoretinopathy (PVR)[56,57].

The MMPs role in the retinal pathological processes, principally in inflammatory and in the oxidative stress, is reported in Table 2. 
Table 2. MMPs, ADAMs and ADAMTSs expressed by RPE Cells and their involvement in different biological processes $(\uparrow \uparrow=$ relevant upregulation; $\uparrow=$ upregulation; $-=$ no regulation; $\downarrow=$ downregulation; $\uparrow \downarrow=$ both upregulation and downregulation observed)

\begin{tabular}{|c|c|c|c|}
\hline \multicolumn{4}{|c|}{ MMP-1, MMP-2, MMP-3, MMP-9 are expressed in RPE cells } \\
\hline Process & $\begin{array}{c}\text { MMP and TIMP } \\
\text { involved }\end{array}$ & Notes & References \\
\hline $\begin{array}{l}\text { Neo- } \\
\text { angiogenesis } \\
\text { (VEGF and } \\
\text { COCL2) }\end{array}$ & $\begin{array}{l}\uparrow \text { MMP-9, MMP- } \\
2 \\
\text { (after VEGF and } \\
\text { chemical } \\
\text { hypoxia) }\end{array}$ & $\begin{array}{l}\text { - Feedback positive } \\
\text { between MMP-9 and } \\
\text { VEGF } \\
\text { - Feedback negative } \\
\text { between MMP-2 and } \\
\text { VEGF } \\
\text { - Probably MMP-9 is not } \\
\text { constitutively expressed } \\
\text { but secreted only in } \\
\text { inflammatory cases } \\
\text { - MMP-9 reduce VEGF } \\
\text { expression through a } \\
\text { direct stimulation on cells } \\
\text { facilitating } \\
\text { neovascularization. }\end{array}$ & $\begin{array}{l}{[52]} \\
{[55]} \\
{[58]} \\
{[59]} \\
{[60]} \\
{[61]} \\
{[62]} \\
{[63]}\end{array}$ \\
\hline Oxidative stress & $\begin{array}{l}\downarrow \text { MMP-2, -14 } \\
\downarrow \text { TIMP2 }\end{array}$ & $\begin{array}{l}\text { - Both MMP-14 and } \\
\text { TIMP-2 are essentials to } \\
\text { reduce the loss of MMP-2 } \\
\text { activation } \\
\text { - MMP-14 is a possible } \\
\text { therapeutic target }\end{array}$ & $\begin{array}{l}{[52]} \\
{[64]} \\
{[65]} \\
{[66]}\end{array}$ \\
\hline \multicolumn{4}{|c|}{ ADAM9, ADAM10, ADAM17 are expressed in RPE cells } \\
\hline Inflammation & $\uparrow$ ADAM10, 17 & $\begin{array}{l}\text { - Shedding of } \\
\text { proinflammatory } \\
\text { mediator } \\
\end{array}$ & [67] \\
\hline Migration & $\uparrow$ ADAM10 & $\begin{array}{l}\text { - ADAM10/E-cadherin } \\
\text { interaction regulates } \\
\text { inflammatory diseases }\end{array}$ & [68] \\
\hline $\begin{array}{l}\text { Development of } \\
\text { the retina }\end{array}$ & $\begin{array}{l}\uparrow \text { ADAM9, 10, } \\
17\end{array}$ & & [69] \\
\hline $\begin{array}{l}\text { Ectodomain } \\
\text { shedding }\end{array}$ & $\begin{array}{l}\uparrow A D A M ~ 9,10, \\
17\end{array}$ & $\begin{array}{l}\text { The activation of ADAM17 } \\
\text { by VEGF suggests a role in } \\
\text { the neovascularization of } \\
\text { the retina }\end{array}$ & $\begin{array}{l}70] \\
{[71]} \\
{[72]}\end{array}$ \\
\hline $\begin{array}{l}\text { Epidermal } \\
\text { integrity }\end{array}$ & ADAM10, 17 & $\begin{array}{l}\text { - ADAM10 main sheddase } \\
\text { for notch receptors. } \\
\text { - ADAM10 and } 17 \\
\text { involved in epidermal } \\
\text { integrity } \\
\end{array}$ & $\begin{array}{l}{[73]} \\
{[74]} \\
{[75]}\end{array}$ \\
\hline
\end{tabular}




\begin{tabular}{|l|l|}
\hline \multicolumn{3}{|c|}{ ADAMTS-1, ADAMTS-3, ADAMTS-5, ADAMTS-7, ADAMTS-9 are expressed in } \\
RPE cells \\
\hline \begin{tabular}{l|l|l|c|} 
Inflammatory and & $\uparrow$ ADAMTS-1, & $\bullet$ Compromising the & {$[76]$} \\
Neo-angiogenesis & ADAMTS-6, & retina structure & {$[77]$} \\
& ADAMTS-9 & & {$[78]$} \\
\hline
\end{tabular}
\end{tabular}

\subsubsection{MMPs in Choroidal Neovascularization: controversial in MMP-2 and -9 role and VEGF mechanism}

In the CNV (Choroidal Neovascularization) newly formed vessels originate from the choroid and release fluids in the subretinal space, causing reversible visual loss that in this conditions could evolve in permanent loss of central vision [79]. Unaltered production of MMPs from RPE cells can help to modify their proteolytic activity in the subretinal space and participate, together with the endothelial cells, to regulation of choroidal neovascularization [80,81]. Choroidal neovascular membranes surgically removed from patients suffering from AMD also show a strong expression of some MMPs, indicating that they could cooperate in the progression of choroidal angiogenesis [57].

In the eye, high levels of MMP-9 and MMP-2 have been found in human diabetic vitreous fluids, and in the areas of new vessel formation [82,83], suggesting that these enzymes can contribute to the pathogenesis of retinal neovascular diseases [84].

Currently, knowledge about MMP-2 and MMP-9 involvement in AMD pathogenesis and also in CNV development, is rather controversial. In particular, MMP-2 and -9 are the metalloproteinases most studied for AMD until now for their specificity for gelatin and collagen.

Concerning MMP-2, a decreased level in BrM, i.e. a positive association between MMP-2 and CNV was reported by some studies [55, 85] but, on the contrary, a protective role of MMP-2 has been shown by other studies [86]. The research on the involvement of MMP-9 in AMD is vague as well. In fact during macular degeneration, some studies showed a decreased level of MMP-9 in choroidal neovascular membranes [59] and in serum [86], meanwhile a MMP-9 growth was found in plasma [87], in choroidal neovascular membranes [88], and in the aqueous humor $[89,90]$. Furthermore, MMP-9 polymorphism was studied in order to better understand the CNV process. Fiotti et al. [62] found a relationship between polymorphisms in MMP-9 and neovascularization in AMD. In addition to this hypothesis, Liukevicene et al. [63] reported the significant role of MMP-9 Rs3918242 (C $\rightarrow$ T) single nucleotide polymorphism in the development of AMD, and the effect was more pronounced in people aged less than 65. To arrest the pathological angiogenesis of CNV, typical of wet AMD, is considered as an important strategy to limit the development of AMD. In particular, the main angiogenic factor in the retina able to promote neovascularization is the vascular endothelial growth factor (VEGF) [91,92]. VEGF is a growth factor able to upregulate the expression of MMPs in RPE cells [52, 60]. 
In cancer vascularization, the role of MMPs in regulating VEGF factor release is well known [93]. However, how MMPs modulate the secretion of VEGF from RPE cells is still under investigation. Holborn et al. [59], evaluated the involvement of MMP-9 and MMP-2 altered gene expression in the secretion of VEGF in RPE cells. In hypoxic conditions, RPE cells upregulate the expression of MMP-2 and MMP-9 and while MMP-9 has a positive feedback on VEGF production and secretion, MMP-2 slightly reduces them. The hypothesis was that MMP-9 could work as a proteolytic promoter on basement membrane and ECM components but also could stimulate the VEGF expression through a direct stimulation on cells thus facilitating neovascularization.

\subsubsection{MMP-14 and TIMP-2: involvement in proMMP-2 activation.}

MMP-14 is one of the most studied enzymes among the Membrane-type MMPs. It is a proteolytic enzyme that has a broad substrate specificity, especially against ECM components: fibrillar collagens (type I, II, III), laminin1 and -5, fibronectin, vitronectin, fibrin and aggrecan [94]. MT1-MMP degrades ECM components directly, and indirectly by activating proMMP-2 forming a trimolecular complex with TIMP-2. In fact, MMP-2 activation process requires two MT1-MMP molecules bound to forming a dimeric interaction through their hemopexin and transmembrane domain. Dimeric MT1-MMP is bound to its endogenous inhibitor, TIMP-2 (Tissue Inhibitors Metalloproteinases), resulting in a homodimeric complex (MT1-MMP-TIMP2-MT1-MMP) that allows MT1MMP to cleave the propeptide of proMMP-2 [95]. For this mechanism in the retina, RPE cells express high levels of proMMP-2 and active MMP-2, but also of TIMP-2 and MMP-14 [52, 64, 65].

As reported by Elliot et al. [66] MMP-14 and TIMP-2 are crucial to reduce the loss of MMP-2 activation induced by oxidative stress in RPE cells. The prevention of the dysregulation of the components of the trimolecular complex is therefore fundamental, suggesting that these enzymes can be possible therapeutic targets. 


\subsection{ADAMs in RPE cells}

ADAMs (a disintegrin and metalloproteinase) belong to the metzincin superfamily and together with snake venom metalloproteinases and ADAMTSs constitute the Adamalysin subfamily of zinc metalloproteinases (Table 2). ADAMs is a family of transmembrane and secreted proteins with functions in cell adhesion and proteolytic processing of ectodomain of cell surface receptors and signal molecules. ADAMs structure is constituted by a Metalloprotease domain and a unique Disintegrin receptor binding integrin domain, which inspires their name. Similarly to MMPs, their domain structure consists of a pro-domain, a metalloprotease domain, a disintegrin domain, a cysteine rich domain, an EGF-like domain, a transmembrane domain and a cytoplasmic tail.

ADAMs are involved in multiple biological events including proteolysis, cell adhesion, cell fusion, cell proliferation and cell migration and therefore play a pivotal role in developmental processes. Proteolysis is the best established ADAMs function, and the cleavage of transmembrane proteins, known as "ectodomain shedding" has emerged as a principal biological event. This process mainly affects type I and type II transmembrane proteins including growth factors, cytokines, chemokines and adhesion molecules [96].

ADAMs have numerous functions in the retina involved in the cell-cell and cell-matrix interactions, in the proteolytic shedding of other membranes proteins and in the intracellular signal transduction [97,98].

At the retina level, ADAMs are involved in different processes and the most significant are summarized in Table 2:

- Development of the retina: ADAMs are involved in the development of the retina, but there is insufficient knowledge of the expression of ADAMs during retinal development. As reported by Yan et al. [99], ADAMs are expressed in different layers of the developing retina, but with a partial overlapping. The authors demonstrated that the mRNAs of ADAM9, ADAM10 and ADAM17 are expressed in the RPE. In particular, ADAMs may play a role in the development of RPE, probably by remodeling the extracellular matrix between RPE and external segments of the photoreceptors. Other studies confirmed that both ADAM10 and ADAM17 are widely expressed also in human retina during the embryonic period, showing an important role in maintaining epidermal integrity and resulting essential for the determination of cell fate, angiogenesis, cell migration and wound healing [69].

- Ectodomain shedding: ADAMs are the most important proteinases that mediate the ectodomain shedding through an activity similar to that of $\alpha$-secretase. It is known that ADAM9, ADAM10 and ADAM17 are the principal proteases involved in the activation of TNF- $\alpha$ and EGF receptor pathways by shedding of pro-TNF- $\alpha$ and EGF receptor ligands [70,71]. ADAM10 and ADAM17 ectodomain shedding activity has a large amount of substrates including cytokine receptors, TNF receptor, EGF receptor, adhesion molecules, transformant-growth factor, and VEGF receptors [96,100]. The involvement of ADAM17 by VEGF-A activation in vascular endothelial cells suggested a possible role in regulating neovascularization of the retina [72]. In fact, after the stimulation by VEGF-A, ADAM17 is able to shed VEGF2 promoting the cascade signaling. 
- Migration and invasion of RPE cells: As reported by Park et al., ADAMs might be involved in the migration and invasion of RPE cells through the control of E-cadherin expression and secretion of epithelial-mesenchymal transition (EMT) cytokines as TGF- $\beta$ [68]. ADAM10/E-cadherin interaction represents a mechanism that regulates many inflammatory epidermal diseases, which are characterized by loss of E-cadherin expression and loss of epithelial integrity [101]. Loss of this interaction generally affects the adhesion of epithelial cells and cell migration. There are no specific data on the modulation of EMT processes mediated by ADAM10 in the eye diseases.

- Inflammatory processes: recent studies support a role for ADAMs in mediating inflammation by the shedding of pro-inflammatory mediators as TNF- $\alpha$ [67]. The authors explored the expression of ADAM10 and 17 in postmortem eyes and in experimental model of AMD in which $\beta$-amyloid (A $\beta)$, a drusen component, promotes proinflammatory events. It was shown that older postmortem eyes expressed higher levels of ADAM10 and 17, mostly in RPE and drusenoid deposits.

- Epidermal integrity: both ADAM10 and ADAM17 have an important role in maintaining epidermal integrity through Notch-mediated regulation signaling [73-74]. Studies using ADAM10 complete knockout mice have suggested a role of this protease in the Notch1 cleavage (an independent splitting within the extracellularjuxtamembrane region of Notch) during mouse embryogenesis but also in adults. The results indicate that ADAM10 functions as the main sheddase for all three Notch receptors. In addition, loss of ADAM9 function causes a disorganization of RPE cells, resulting in the interruption of photoreceptor cell functions [75].

\subsection{ADAMTSs in RPE cells}

Considerable attention has been reserved to the ADAMTSs (A Disintegrin and Metalloproteinase with Thrombospondin motifs) enzymes that are multi-domain zinc metalloendopeptidases with important roles in tissue morphogenesis and patho-physiological remodeling, in inflammation and in vascular biology. Structurally the ADAMTSs are similarly organized as the other metalloproteinases, MMPs and ADAMs. Basically, ADAMTSs present two main structures: a proteinase domain and an ancillary domain. More specific is the ancillary domain which is composed by one or more thrombospondin type 1 sequence repeats and it gives variability between ADAMTS members [102].

The family of the ADAMTS proteins, as the others zinc metalloproteinases, is involved in different processes at the retina level. First of all, the discovery of ADAMTS expression in RPE cells extends the number of enzymes potentially involved in the turnover of the retinal extracellular matrix both in normal and pathological conditions. From the literature, the transcription of several ADAMTS genes into the ARPE19 ocular cell line was first described by Bevitt et al. [78]. In particular, the authors showed that the mRNAs of ADAMTS-1, ADAMTS-3, ADAMTS-5, ADAMTS-7 and ADAMTS-9 are expressed in RPE cells, while the mRNA for ADAMTS-2, ADAMTS-4, ADAMTS-8 and ADAMTS-6 were not detected. 
Moreover, the secretion of proteoglycans from RPE cells in the matrix is fundamental for the turnover of some proteoglycan molecules in IPM and Bruch Membrane and, as evidenced by Hollyfield et al. [103], requires the action of particular ADAMTSs.

ADAMTS-2 and ADAMTS-3 are procollagen N-pro-peptidases (PCNP1 and PCNP2, respectively) able to process the type I, II and III of collagens in Bruch's membrane [104,105]. For other ADAMTSs there are no data on their activity at the retina level; it is therefore difficult to state what roles these enzymes can have at the level of the retinal extracellular matrix. They have similar structural domains to the other members of the ADAMTS family and therefore could show similar targets for ECM proteins.

\subsubsection{ADAMTSs involved in inflammatory processes and in retinal neovascularization}

In the human retina hypoxia and migration of RPE cells are characteristic of senile macular degeneration (ARMD) and other retinal disorders such as proliferative vitreoretinopathy (PVR) and diabetic vitreoretinopathy (DVR). These processes are known to be mediated by upregulation of some MMPs, but Bevitt et al. [78], suggested the possibility that ADAMTS proteins may also be involved. The authors observed a potent upregulation of some ADAMTSs by human RPE cells, in response to tumor necrosis factor $\alpha$ (TNF- $\alpha$ ). TNF $\alpha$ is known to play a role in the development of neovascularization in the murine retina in response to hypoxia [76]. In particular, the expression of various ADAMTSs were observed after stimulation with TNF $\alpha$ : ADAMTS-1, -6 and -9 transcripts, expressed in ARPE-19 cells, showed a potent upregulation [77]. ADAMTSs are involved principally in inflammatory conditions of the retina. In fact, especially in ARMD they are able to compromise the structure of the retinal matrix. In conclusion, further studies are needed to deeply dissect the role of ADAMTSs in pathological neo-angiogenesis.

\section{Modulation of MMPs and ADAMs activity in AMD.}

For the treatment of AMD, the modulation of metalloproteinase activity could be a therapeutic tool to exploit considering metalloproteinase role in the progression of the pathology. Herein, we analyze the molecules and the technologies recently described as modulators of MMP activity that could have an important role as therapeutic agents in this pathology. Further studies are needed to clarify the role of these molecules with a monotherapy or in combination with other drugs or technologies (Table 3). 
Table 3. Modulation of MMPs and ADAMs activity in AMD

( $\uparrow=$ upregulation; - = no regulation; $\downarrow=$ downregulation; $\downarrow \downarrow=$ relevant downregulation)

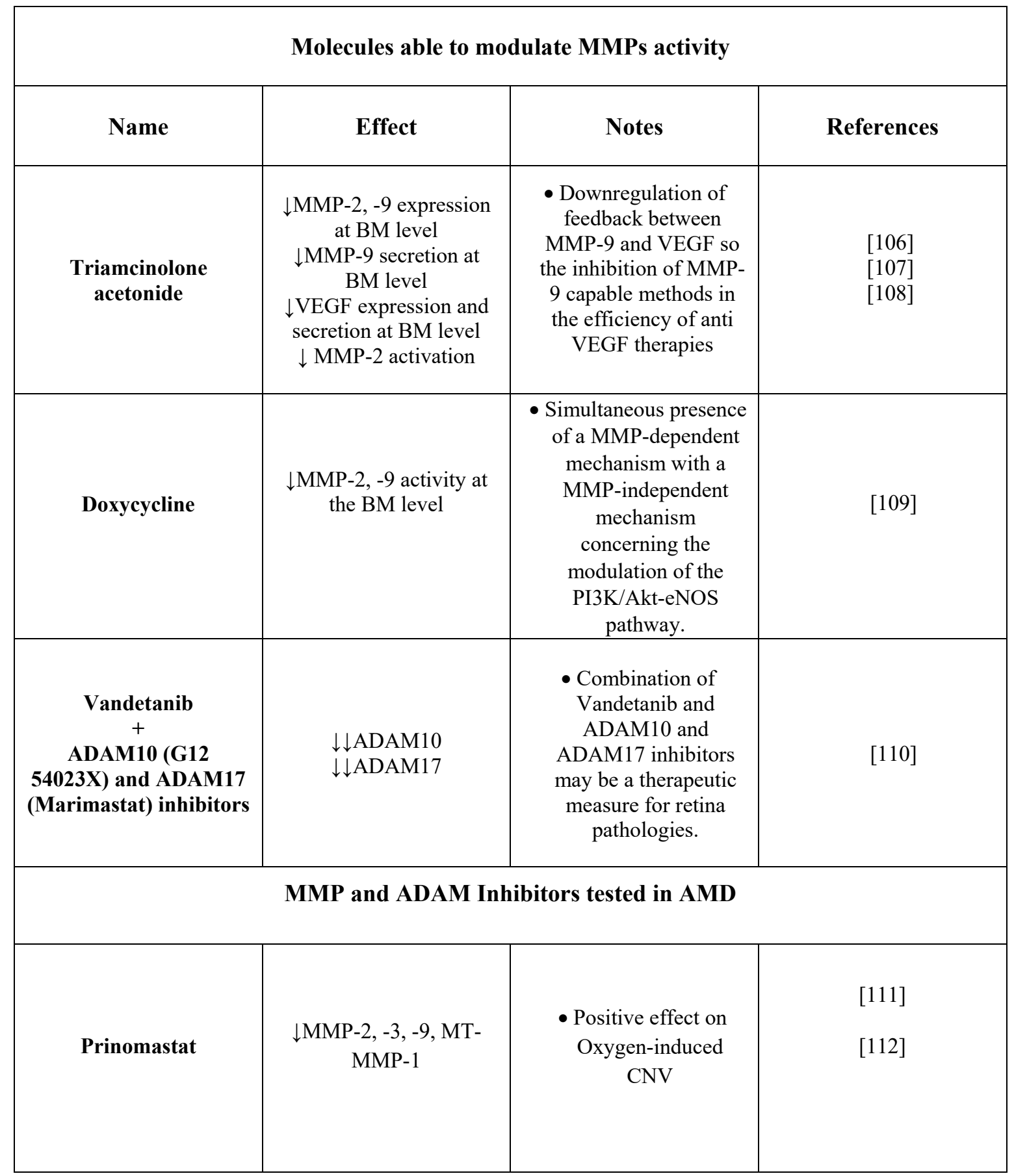




\begin{tabular}{|c|c|c|c|}
\hline BPHA & $\downarrow$ MMP-2, -9,-14 & $\begin{array}{r}\bullet \downarrow \text { MMP degradation } \\
\text { of gelatin and } \\
\text { thickness of CNV } \\
\text { lesion }\end{array}$ & {$[113]$} \\
\hline Batimastat & $\downarrow$ MMP-1,-2,-3,-7,-9 & $\begin{array}{c}\text { - Suppress } \\
\text { neovascularization }\end{array}$ & {$[114]$} \\
\hline
\end{tabular}

\subsection{MMP and ADAM Inhibitors tested in AMD}

In recent years, ADAMs and MMPs have been studied as potential therapeutic targets. Several synthetic inhibitors of these metalloproteinases have been developed and some of them have been proposed as investigative or therapeutic tools for retinal diseases. Unfortunately, due to the high degree of homology between the members of the MMPs and ADAMs family as well as the complexity of their physiological functions, to date the efforts spent in the development of synthetic inhibitors have not led to the desired results.

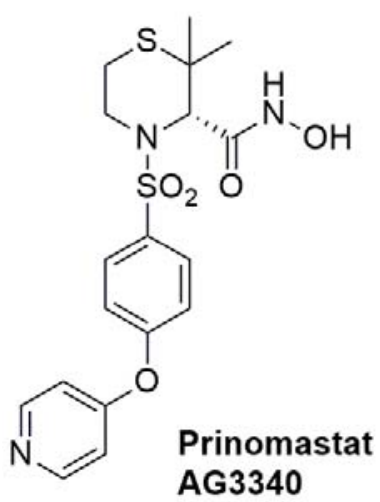<smiles>CNC(=O)[C@H](Cc1ccccc1)NC(=O)C(C[In]C(C)C)C(CSc1cccs1)C(=O)NO</smiles>

Batimastat<smiles>O=C(N[C@@H](Cc1ccccc1)C(=O)NO)c1ccc(-c2ccccc2)cc1</smiles>

Figure 4 Chemical structure of the principal MMP inhibitors tested in AMD

Prinomastat: AG3340, also called Prinomastat (Figure 4), is the first synthetic matrix metalloproteinase inhibitor with selective inhibitory activity on MMP-2, MMP-9, MMP-3, and MT-MMP1. It was developed by Agouron Pharmaceuticals Inc [110] until Phase II/III study, demonstrating a good pharmacokinetic profile in reducing neovascularization in new born mice and in a hypoxia-induced model of retinopathy. In 2004 the positive effect of AG3340 in the early stages of laser induced rat CNV model was reported. Hypothetically, it could be used in combination with photodynamic therapies to inhibit recurrence from temporarily closed new vessels [112]. Further 
investigations were performed by Garcia et al. [115], demonstrating the positive effect of Prinomastat on oxygeninduced CNV using systemic administration.

BPHA: $N$-Biphenyl sulfonyl-phenylalanine hydroxamic acid (BPHA, Figure 4) is a selective MMP inhibitors for MMP-2, MMP-9 and MMP-14, showing antiangiogenic properties. BPHA effect on CNV was studied by Kohri et al. [113] with good results on reducing the development of the pathology. In particular on laser-induced $\mathrm{CNV}$, BPHA reduced the MMP degradation of gelatin in a dose-dependent fashion. Moreover, BPHA caused a reduction in the thickness of CNV lesion in patients.

Batimastat (BB-94): Batimastat (Figure 4) is a potent broad-spectrum MMPs inhibitor for MMP-1, MMP-2, MMP-9, MMP-7 and MMP-3 and also ADAM17. In a murine model of retinal neovascularization, BB-94 has been shown to suppress neovascularization due to a disruption of potential matrix interactions necessary for the maintenance of survival and motility of endothelial cells [114]. BB-94 can be used only at low doses (1 mg / kg), while at higher doses it has been described as toxic in in vivo models.<smiles>CC1(C)O[C@H]2C[C@H]3C4CCC5=CC(=O)C=CC5C4[C@H](O)C[C@]3(C)[C@H]2O1</smiles>

Triamcinolone acetonide<smiles>CNC(=O)[C@H](NC(=O)[C@H](CC(C)C)[C@@H](O)C(=O)NO)C(C)(C)C</smiles><smiles>CC(=O)C1=C(O)[C@@H](N(C)C)C2CC3C(=C(O)[C@]2(C)C1=O)C(=O)c1c(O)cccc1C3C</smiles>

Doxycycline<smiles>CNC(=O)[C@H](NC(=O)[C@H](CCCc1ccccc1)C(C)(C)C)[C@@H](C)N(O)C=O</smiles>

GI254023X

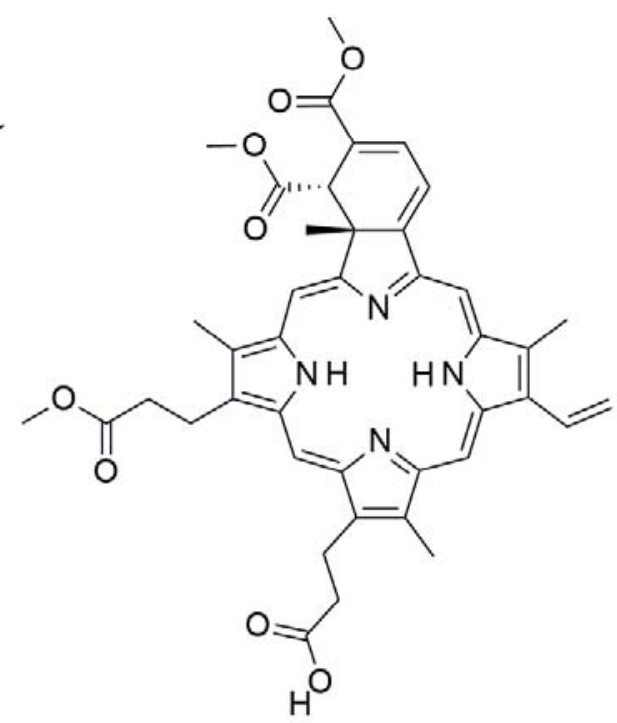<smiles>COc1cc2c(Nc3ccc(Br)cc3F)ncnc2cc1OCC1CCN(C)CC1</smiles>

Vandetanib

Verteporfin 
Figure 5. Chemical structures of Triamcinolone acetonide, Docycycline, GI254023X, Marimastat, Verteporfin and Vandetanib.

Triamcinolone acetonide: Triamcinolone acetonide (TA, Figure 5) is a corticosteroid and is one of the first drugs evaluated for the treatment of choroidal neovascularization (CNV) secondary to AMD [108].

Triamcinolone is able to reduce the expression of MMP-2 and MMP-9 in choroidal endothelial cells and prevents endothelial cell migration by inhibiting MMP-2 activation [106]. Similarly Webb et al. [107], showed that TA decreases the gene expression of MMP-2 and MMP-9 and inhibits the secretion of MMP-9 by RPE cells induced by chemical hypoxia or VEGF (see CNV paragraphs). Basically, TA inhibits the positive feedback regulation between MMP-9 and VEGF under hypoxic conditions through inhibition of the gene expression of MMP-9.

Doxycycline: Doxycycline (Figure 5) is a semisynthetic tetracycline antibiotic with strong antimicrobial properties, used principally for acne treatment, infective diarrhea, anthrax, Lyme disease [116]. For ages, it has been used as a safe drug in clinical setting as antibiotics but it also possesses versatile non-antibiotic properties deeply explored in ocular angiogenesis. In fact, many studies reported the effective inhibitory effect of doxycycline on ocular angiogenesis with oral or topical administration [109, 117, 118]. Moreover, the co-administration of doxycycline and bevacizumab improves the inhibitory effects of the monotherapy on CNV in animal model [119]. So far, the Doxycycline mechanism is not completely understood but some evidences suggested that doxycycline antiangiogenic effect may be a consequence of MMPs inhibition.

In $2013 \mathrm{Su}$ et al. [120] reported a potential Doxycycline mechanism demonstrating the simultaneous presence of a MMP-dependent mechanism with an MMP-independent mechanism concerning the modulation the PI3K/AkteNOS path. MMP-2 and MMP-9 are involved in Doxycycline-mediated vascular epithelial cell growth on CNV in vivo.

Mass spectrometry studies indicated Doxycycline as a non-competitive MMP inhibitor, interacting with the zinc or calcium atoms within the structural center of these proteins necessary for stability [121]. Other studies showed that Doxycycline effectively reduces the progression of CNV, inhibiting the activity of MMP-2 and MMP-9 gelatinases [109]. These results are in agreement with previous studies indicating the contribution of MMP-2 and MMP-9 in CNV progression. These results suggest that Doxycycline, when orally administered, can reach the choroid and inhibit proteolytic enzymes that remodel the membrane and may therefore reduce neovascularization.

Vandetanib and ADAM inhibitors co-administration: Vandetanib (Figure 5), an oral bioavailable kinase inhibitor, is considered a potential post-operative adjuvant chemotherapy drug to inhibit proliferation, progression, migration and the survival of tumor cells, as it plays an important role in regulating the VEGFR and EGFR signaling pathways [122].

A recent research studied the effect of Vandetanib on the expression of ADAMs, epithelium marker and mesenchymal markers, to evaluate their application in the clinical setting, as new targets or drugs to prevent 
progression of AMD [110]. The researchers used EBV-infected RPE cells (ARPE19 / EBV), as an in vitro model of CNV or PVR, which expressed mesenchymal phenotypes and which secreted VEGF.

Regarding ADAM10 and ADAM17, the treatment of ARPE19/EBV cells with Vandetanib led to the downregulation of their expression in a dose-dependent manner. Moreover, the activity of these ADAMs has been effectively blocked after the co-treatment with ADAM10 (GI254023X) and ADAM17 (Marimastat) inhibitors and low-dose of Vandetanib. The combination of Vandetanib with an ADAM inhibitor influenced the signaling pathway induced by VEGF. Moreover, the combination of low-dose Vandetanib with an ADAM10 or ADAM17 inhibitor attenuated the migratory capacity of EBV-infected ARPE19 cells in an in vitro model of CNV compared to treatment with a single drug (Vandetanib) previously tested. The results of the present study suggested that the inhibition of VEGF-mediated signal transduction cascade (at the basis of pathological migration of RPE cells) through co-treatment of Vandetanib and an ADAM inhibitor, may be a suitable therapeutic measure to treat neovascular AMD or other retinal pathological conditions.

Photodynamic therapy and MMPs: The photodynamic therapy (PDT) of Verteporfin (Figure 5) (Visudyne, Ciba Vision Corp., Duluth, GA, USA) was found useful in clinical studies in retinal diseases [123,124]. However, the use of PDT showed a very high recurrence percentage that exceeds the benefits of its use. Tatar et al. [125], verified that PDT induced firstly a temporary decrease in MMP-9 expression level in the retina but in a second time, MMP9 expression increased again due to the dual role of MMP in angiogenic process. In fact MMP inhibitors play an inhibitory activity on microvessel formation at the begin of angiogenesis process but in the angiogenesis growth phase they prevent vascular regression [126]. However, a similar dual role of MMPs should be expected in the vascularisation and involution stages of CNV. In fact, MMPs inhibitors can be used as PDT adjuvants: in longer intervals after PDT may additionally inhibit CNV rather than the PDT used as the only therapy for neovascular AMD.

Nanosecond laser: MMPs role in AMD is controversial (see paragraph Metalloproteinases) and it is demonstrated that the administration of MMP-2 and MMP-9 in activate form could improve the BrM permeability [66]. Along this line, an alternative technique, the nanosecond laser, was used to induce RPE-mediated release of MMPs [127]. One year of clinical trial demonstrated that a single laser application can improve the functionality of the surface of the macula.

\section{Conclusion}

Age-related macular degeneration (AMD) is a multifactorial disorder characterized by an ECM remodeling that is generally pathological. The main enzymatic group involved in the degradation of ECM is the superfamily of Metzincins, that includes Matrix metalloproteinases (MMPs), ADAMs and ADAMTSs. Many recent findings highlight the importance of metzincins in the development of AMD. Alteration of these enzymes plays a very important role in AMD pathogenesis, especially in the early phases of choroidal neovascularization. 
We have separately analyzed the different groups of zinc metalloproteinases: MMPs, ADAMs and ADAMTSs. Many metzincins are expressed in the human retina: MMP-2, MMP-9, MMP-14, ADAM9, ADAM10, ADAM17, ADAMTS-1, ADAMTS-3, ADAMTS-5, ADAMTS-7 and ADAMTS-9 and may provide clues to the role of the matrix-degrading proteases in the pathogenesis of the complex phenotype of AMD.

In particular, the localization of MMPs in the areas of new vessel formation and in the enveloping Bruch's-like membrane suggests that MMPs may be cooperatively involved in the progressive growth of choroidal neovascular membranes in AMD. However, knowledge on MMPs action in AMD pathogenesis is still controversial, because different studies demonstrates the protective effect of these enzymes.

Over the last decade, numerous therapeutic options have become available for neovascular AMD, most notably anti-VEGF medications. In order to be effective, anti-VEGF drugs must be used relatively early in the disease onset, before scar formation has occurred. These drugs have the potential to increase the risk of thromboembolic events in an already susceptible population.

The use of molecules or technologies able to modulate these enzymes with a potential therapeutic benefit in the treatment of many proliferative retinopathy conditions was analyzed, considering metzincins deeply involved in the process of neovascularization. So far, different promising molecules were proposed as MMP, ADAM and ADAMTS modulator useful in AMD treatment, or even in association with other promising treatment.

In conclusion, the complexity of the research field examined points out that AMD therapy has changed dramatically over the last decade. While our knowledge of the molecular mechanisms and the role of metalloproteinases involved in AMD is increasing, new treatments are emerging and innovative therapeutic approaches to AMD can be provided.

\section{LIST OF ABBREVIATIONS}

$\mathrm{ADAM}=\mathrm{A}$ disintegrin and metalloproteinase

ADAMTS $=$ A disintegrin and metalloproteinase with thrombospondin motifs

$\mathrm{AKt} \quad=$ Protein kinase $\mathrm{B}$

AMD = Age-related macular degeneration

ARMS2 / HTRA1 = Age-related maculopathy $2 / \mathrm{HtrA}$ peptidase serine 1

BPHA $=N$-Biphenyl sulfonyl-phenylalanine hydroxamic acid

$\mathrm{BrM}=$ Bruch's Membrane

$\mathrm{C} 2=$ Complement component 2

C3 = Complement component 3

CFB $=$ Complement $\mathrm{B}$ 


\begin{tabular}{|c|c|}
\hline $\mathrm{CFH}$ & $=$ Complement gene $\mathrm{H}$ \\
\hline $\mathrm{CNV}$ & $=$ Choroidal neovascularization \\
\hline DVR & $=$ Diabetic vitreoretinopathy \\
\hline ECM & $=$ Extracellular matrix \\
\hline EL & $=$ Elastin layer \\
\hline EMT & $=$ Epithelial-to-mesenchymal transition \\
\hline $\mathrm{E} / \mathrm{N}$ & $=$ Entactin $/$ nidogen \\
\hline FN-439 & $=$ Tetrapeptidyl hydroxamic acid \\
\hline GA & $=$ Geographic atrophy \\
\hline GPI & $=$ Glycosylphosphatidylinositol \\
\hline HSPGs & $=$ Heparin sulphate proteoglycans \\
\hline ICL & $=$ Inner collagen layer \\
\hline IL-1 & $=$ Interleukin-1 family \\
\hline IPM & $=$ Interphotoreceptor matrix \\
\hline MAPK & $=$ Mitogen-activated kinase protein \\
\hline MMPs & $=$ Matrix metalloproteinases \\
\hline Notch & $=$ Notch-mediated regulation signaling \\
\hline OCL & $=$ Outer Collagene Layer \\
\hline PCNP & $=$ Procollagen Npropeptidases \\
\hline PDT & $=$ Photodynamic therapy \\
\hline PGs & $=$ Proteoglycans \\
\hline PI3K & $=$ Phosphatidylinositide 3-kinases \\
\hline PVR & $=$ Proliferative Vitreoretinopathy \\
\hline RPE & $=$ Retinal pigment epithelium \\
\hline RPE-BL & $=\mathrm{RPE}$ basal lamina \\
\hline RPECs & $=$ Retinal Pigment Epithelium cells \\
\hline SRF & $=$ Sorafenib \\
\hline TA & $=$ Triamcinolone acetonide \\
\hline TGF-2 & $=$ Transforming growth factor alfa \\
\hline
\end{tabular}


TIMP $=$ Tissue inhibitor of metalloproteinase

TNF- $\alpha=$ Tumor necrosis factor- $\alpha$

VEGF = Vascular endothelial growth factor

VEGFR $=$ Vascular endothelial growth factor receptor

\section{Consent for publication}

Not applicable.

\section{Conflict of interest}

The authors declare no conflict of interest, financial or otherwise.

\section{Acknowledgments}

The present study was supported by funding from M-era.Net 2016 European programme to project "Biomembrane". 


\section{References}

[1] Curcio CA, Presley JB, Malek G, Medeiros NE, Avery DV, Kruth HS. Esterified and unesterified cholesterol in drusen and basal deposits of eyes with age-related maculopathy. Exp Eye Res 2005; 81: 731-741.

[2] Hogan MJ. Role of the retinal pigment epithelium in macular disease. Trans Am Acad Ophthalmol Otolaryngol 1972; 1: 64-80.

[3] Murphy G. The ADAMs: signalling scissors in the tumour microenvironment. Nat Rev Cancer 2008; 8: 929941.

[4] Jager RD, Mieler WF, Miller JW. Age-related macular degeneration. N Engl J Med 2008; 358: 2606-2617.

[5] Lim LS, Mitchell P, Seddon JM, et al. Age-related macular degeneration. Lancet 2012; 379: 1728-1738.

[6] Fritsche LG, Igl W, Bailey JN, et al. A large genome-wide association study of age-related macular degeneration highlights contributions of rare and common variants. Nat Genet 2016; 48: 134-143.

[7] Vingerling JR, Dielemans I, Bots ML, et al. Age-related macular degeneration is associated with atherosclerosis. The Rotterdam Study. Am J Epidemiol 1995; 142: 404-409.

[8] Seddon JM, Ajani UA, Sperduto RD. Dietary carotenoids, vitamins A, C, and E, and advanced age-related macular degeneration. Eye Disease Case-Control Study Group, JAMA, 1994; 272: 1413-1420.

[9] Friedman DS, O'Colmain BJ, Muñoz B, et al. Prevalence of age-related macular degeneration in the United States. Arch Ophthalmol 2004; 122: 564-572.

[10] Chang MA, Bressler S, Munoz B, West S. Racial Differences and Other Risk Factors for Incidence and Progression of Age-Related Macular Degeneration: Salisbury Eye Evaluation (SEE) Project. IOVS 2008; 49: 2395-2402.

[11] Nano ME, Lansingh VC, Pighin MS, et al. Risk factors of age-related macular degeneration in Argentina. Arq Bras Oftalmol 2013; 76: 80-84.

[12] McCarty CA, Mukesh BN, Fu CL, et al. Risk factors for Age-related maculopathy. Arch Ophthalmol 2001; 119: $1455-1462$.

[13] Rowan S, Jiang S, Korem T, et al. Involvement of a gut-retina axis in protection against dietary glycemiainduced age-related macular degeneration. Proc Natl Acad Sci USA 2017; 114: 4472-4481.

[14] Armstrong RA, Mousavi M. Overview of Risk Factors for Age-Related Macular Degeneration (AMD). J Stem Cells 2015; 10: 171-191.

[15] Chakravarthy U, Evans J, Rosenfeld PJ. Age related macular degeneration. BMJ 2010; 340:c981.

[16] Johnson LV, Leitner WP, Staples MK, Anderson DH. Complement activation and inflammatory processes in Drusen formation and age related macular degeneration. Exp Eye Res 2001; 73: 887-896.

[17] Edwards AO, Ritter R, Abel KJ, Manning A, Panhuysen C, Farrer LA. Complement factor H polymorphism and age-related macular degeneration. Science 2005; 308: 421-424. 
[18] Gold B, Merriam JE, Zernant J, et al. Variation in factor B (BF) and complement component 2 (C2) genes is associated with age-related macular degeneration. Nat Genet 2006; 38: 458-462.

[19] Jager RD, Mieler WF, Miller JW. Age-related macular degeneration. N Engl J Med 2008; 358: 2606-2617.

[20] Molins B, Romero-Vázquez S, Fuentes-Prior P, Adan A, Dick AD. C-Reactive Protein as a Therapeutic Target in Age-Related Macular Degeneration. Front Immunol 2018; 9: 808.

[21] Nita M, Strzałka-Mrozik B, Grzybowski A, Mazurek U, Romaniuk V. Age-related macular degeneration and changes in the extracellular matrix. Med Sci Monit 2014; 20: 1003-1016.

[22] Kutty RK, Samuel W, Boyce K, et al. Proinflammatory cytokines decrease the expression of genes critical for RPE function. Mol Vis 2016; 8: 1156-1168.

[23] Ferris FL, Davis MD, Clemons TE et al. A simplified severity scale for age-related macular degeneration, Arch Ophthalmol 2005; 123: 1523-1570.

[24] Wong WL, Su X, Li X, et al. Global prevalence of age-related macular degeneration and disease burden projection for 2020 and 2040: a systematic review and meta-analysis. Lancet Glob Health 2014; 2: 106-116.

[25] AREDS-Study-Group. A randomized, placebo-controlled, clinical trial of high-dose supplementation with vitamins $\mathrm{C}$ and $\mathrm{E}$, beta carotene, and zinc for age-related macular degeneration and vision loss. Arch Ophthalmol 2001;119:1417-1436.

[26] Parmet S, Lynm C, Glass RM. Age-Related Macular Degeneration. JAMA 2002; 288: 2358.

[27] Waseem M, Sanaa A. Recent developments in age-related macular degeneration: a review. Clin Interv Aging 2017; 12: 1313-1330.

[28] Bennett N, John L, Likhar N, Agrawal R, Amoaku WM. Clinical Efficacy and Safety of Current Interventions for Choroidal Neovascularization Associated with Rare Diseases: A Systematic Literature Review. Adv Ther 2018; 35: 591-603.

[29] Fritsche LG, Fariss RN, Stambolian D, Abecasis GR, Curcio CA, Swaroop A. Age-related macular degeneration: genetics and biology coming together. Annu Rev Genomics Hum Genet. 2014; 15:151-171.

[30] Chong NH, Keonin J, Luthert PJ, et al. Decreased thickness and integrity of the macular elastic layer of Bruch's membrane correspond to the distribution of lesions associated with age-related macular degeneration. Am J Pathol 2005; 166: 241-251.

[31] Saint-Geniez M, Kurihara T, Sekiyama E, et al. An essential role for RPE-derived soluble VEGF in the maintenance of choriocapillaris. Proc Natl Acad Sci 2009; 106: 18751-18756.

[32] Mullins RF, Sohn EH. Bruch's Membrane: The Critical Boundary in Macular Degeneration. In: Ying GS, ed. Age Related Macular Degeneration, The Recent Advances in Basic Research and Clinical Care 2012; 3: 300.

[33] Małgorzata N, Strzałka-Mrozik B, Grzybowski A, Mazurek U, Romaniuk V. Age-related macular degeneration and changes in the extracellular matrix. Med Sci Monit 2014; 20: 1003-1016.

[34] Sparrrow JR, Hicks D, Hamel CP. The Retinal Pigment Epithelium in Health and Disease. Curr mol med 2010; 10: 802-823. 
[35] Alcazar O, Cousins SW, Striker GE, Marin-Castano ME. (Pro)renin receptor is expressed in human retinal pigment epithelium and participates in extracellular matrix remodeling. Exp Eye Res 2009; 89: 638-647.

[36] Brew K, Nagase H. The tissue inhibitors of metalloproteinases (TIMPs): An ancient family with structural and functional diversity. Biochim Biophys Acta 2010; 1803: 55-71.

[37] Alexander J, Preston J, Bradley MB, et al. Expression of Matrix Metalloproteinases end Inhibitor by Human Retinal Pigment Epithelium. IOVS 1990; 31: 2520-2528.

[38] Rhoades W, Dickson D, Do DV. Potential role of lampalizumab for treatment of geographic atrophy. Clin Ophthalmol 2015; 9: 1049-1056.

[39] a) ClinicalTrials. Gov CHROMA 2016 (https://clinicaltrials.gov/ct2/show/NCT02247479 (SPECTRI).2017 https://clinicaltrials.gov/ct2/show/NCT02247531). b) Holz FG, Sadda SR, Busbee B, et al. Efficacy and Safety of Lampalizumab forGeographic Atrophy Due to Age-Related Macular Degeneration: Chroma and Spectri Phase 3 Randomized Clinical Trials. JAMA Ophthalmol 2018; 6: 666-677.

[40] ClinicalTrials.gov. Clinical study to evaluate treatment with Oracea ${ }^{\circledR}$ for geographic atrophy (TOGA). Available from: https:/clinicaltrials.gov/ct2/show/NCT01782989. NLM identifier: NCT01782989. Accessed on December 17, 2018.

[41] Szeto HH, Birk AV. Serendipity and the discovery of novel compounds that restore mitochondrial plasticity. Clin Pharmacol Ther 2014; 96: 672-683.

[42] ClinicalTrials.gov. A study of MTP-131 topical ophthalmic solution in subjects with diabetic macular edema and non-exudative intermediate age-related macular degeneration (SPIOC-101). Available from:https://clinicaltrials.gov/ct2/show/NCT02314299?term=MTP-131\& rank=4. NLM identifier: NCT02314299. Accessed on December 17, 2018.

[43] Gragoudas ES, Adamis AP, Cunningham ET Jr, et al. VEGF Inhibition Study in Ocular Neovascularization Clinical Trial Group. Pegaptanib for neovascular age-related macular degeneration. N Engl J Med 2004; 351: 2805-2816.

[44] Yonekawa Y, Miller JW, Kim IK. Age-related macular degeneration: advances in management and diagnosis. J Clin Med 2015; 4: 343-359.

[45] Stewart MW. Aflibercept (VEGF Trap-eye): the newest anti-VEGF drug. Br J Ophthalmol 2012; 96: 11571158.

[46] ClinicalTrials.gov. A phase 1, safety, tolerability and pharmacokinetic profile of intravitreous injections of E10030 (anti-PDGF pegylated aptamer) in subjects with neovascular age-related macular degeneration. Available from: https://clinicaltrials.gov/show/NCT00569140. NLM identifier: NCT00569140. Accessed on December 17, 2018.

[47] ClinicalTrials.gov. A safety and efficacy study of E10030 (antiPDGF pegylated aptamer) plus lucentis for neovascular age-related macular degeneration. Available from: https:/clinicaltrials.gov/ct2/ show/results/NCT01089517?term=E10030\&rank=3. NLM identifier: NCT01089517. Accessed on December 17, 2018.

[48] Sing M, Tyag SC. Metalloproteinases as mediators of inflammation and the eyes: molecular genetic underpinnings governing ocular pathophysiology. Int J Ophthalmol 2017; 10: 1308-1318. 
[49] Li G, Hussain AA, Limb GA, Marshall J. Age-Dependent Variation in Metalloproteinase Activity of Isolated Human Bruch's Membrane and Choroid . IOVS 1999; 40: 2676-2682.

[50] Hussain AA, Starita C, Marshall J. Molecular weight size exclusion limit and diffusional status of aging human Bruch's membrane. IOVS 1999; 40: S973.

[51] Liutkeviciene R, Sinkunaite-Marsalkiene G, Asmoniene V, Zaliuniene D. An impact of mutation on MMP$2,-3$ and -9 activity regulation and influence on age-related macular degeneration development: literature review. Biologija 2014; 60: 107-116.

[52] Eichler W, Friedrichs U, Thies A, et al. Modulation of matrix metalloproteinase and TIMP-1 expression by cytokines in human RPE cells. IOVS 2002; 43: 2767-2773.

[53] Plantner JJ, Jiang C, Smine A. Increase in interphotoreceptor matrix gelatinase A (MMP-2) associated with age-related macular degeneration. Exp Eye Res 1998; 67: 637-645.

[54] Kamei M, Hollyfield JG. TIMP-3 in Bruch's membrane: changes during aging and in age-related macular degeneration. IOVS 1999; 40: 2367-2375.

[55] Hussain AA, Lee Y, Zhang JJ, Marshall J. Disturbed Matrix Metalloproteinase Activity of Bruch's Membrane in Age-Related Macular Degeneration. IOVS 2011; 52: 4459-4466.

[56] Hiscott P, Sheridan C, Magee RM, Grierson I. Matrix and the retinal pigment epithelium in proliferative retinal disease. Prog Retinal Eye Res 1999; 18: 167-190.

[57] Mousa SA, Lorelli W, Campochiaro PA. Role of hypoxia and extracellular matrix-integrin binding in the modulation of angiogenic growth factors secretion by retinal pigmented epithelial cells. J Cell Biochem 1999; 74: $135-143$.

[58] Steen B, Sejersen S, Berglin L, Seregard S, Kvanta A. Matrix metalloproteinases and metalloproteinases inhibitors in choroidal neovascular membranes. IOVS 1998; 39: 2194-2200.

[59] Hollborn M, Stathopoulos C, Steffen A, Wiedemann P, Kohen L, Bringmann A. Positive feedback regulation between MMP-9 and VEGF in human RPE cells. IOVS 2007; 48: 4360-4367.

[60] Hunt RC, Fox A, al Pakalnis V, et al. Cytokines cause cultured retinal pigment epithelial cells to secrete metalloproteinases and to contract collagen gels. IOVS 1993; 34: 3179-3186.

[61] Hoffmann S, He S, Ehren M, Ryan SJ, Wiedemann P, Hinton DR. MMP-2 and MMP-9 secretion by RPE is stimulated by angiogenic molecules found in choroidal neovascular membranes. Retina 2006; 26: 454-461.

[62] Fiotti N, Pedio M, Ravalico G. et al. MMP-9 microsatellite polymorphism and susceptibility to exudative form of age-related macular degeneration. Genet Med 2005; 7: 272-277.

[63] Liutkeviciene R, Lesauskaite V, Sinkunaite-Marsalkiene S, et al. The role of matrix metalloproteinases polymorphisms in age-related macular degeneration. Ophthalmic Genet 2013; 9: 149-155.

[64] Marin-Castano ME, Csaky K, Cousins SW. Nonlethal oxidant injury to Human Retinal Pigment Epithelium cells causes cell membrane blebbing but decreased MMP-2 activity. IOVS 2005; 46: 3331-3340.

[65] Ahir A, Guo L, Hussain AA, Marshall J. Expression of metalloproteinases from human retinal pigment epithelial cells and their effects on the hydraulic conducţivity of Bruch's membrane. IOVS 2002; 43: 458-465. 
[66] Elliot S; Catanuto P; Stetler-Stevenson W; Cousins SW. Retinal Pigment Epithelium Protection from OxidantMediated Loss of MMP-2 Activation Requires Both MMP-14 and TIMP-2. IOVS 2006; 47: 1696-1702.

[67] Or C, Wang J, Kojic L, Cui Z, Matsubara JA. 2014. Expression of ADAMs (A Disintegrin and Metalloproteinase) 10 and 17 in Human Eyes and in Experimental Models of Age Related Macular Degeneration (AMD). IOVS 2014; 55: 3460.

[68] Park G, Kim D, Kim Y, Sun H, Yang J, Hur D. Regulation of ADAM10 and ADAM17 by Sorafenib Inhibits Epithelial-to-Mesenchymal Transition in Epstein-Barr Virus-Infected Retinal Pigment Epithelial Cells. IOVS 2015; 56: 5162-5173.

[69] Saftig P, Reiss K. The 'A Disintegrin and Metalloproteases' ADAM10 and ADAM17: Novel drug targets with therapeutic potential. Eur J Cell Biol 2011; 90: 527-35.

[70] Sahin U, Weskamp G, Kelly K, et al. Distinct roles for ADAM10 and ADAM17 in ectodomain shedding of six EGFR-ligands. J Cell Biol 2004; 164: 769-779.

[71] Lim JM, Lee J, Wee W, Joo C. Downregulated expression of ADAM9 in anterior polar cataracts. JCRS 2002; 28: 697-702.

[72] Swendeman S, Mendelson K, Weskamp G, et al. VEGF-A stimulates ADAM17-dependent shedding of VEGFR2 and crosstalk between VEGFR2 and ERK signaling. Circ Res 2008; 103: 916-918.

[73] Weber S, Niessen MT, Prox J, et al. The disintegrin/metalloproteinase ADAM10 is essential for epidermal integrity and Notch-mediated signaling. Development 2011; 138: 495-505.

[74] Murthy A, Shao YW, Narala SR, et al. Notch activation by the metalloproteinase ADAM17 regulates myeloproliferation and atopic barrier immunity by suppressing epithelial cytokine synthesis. Immunity 2012; 36: $105-119$.

[75] Parry DA, Toomes C, Bida L, et al. Loss of the metalloprotease ADAM9 leads toconerod dystrophy in humans and retinal degeneration in mice. Am J Hum Genet 2009; 84: 683-691.

[76] Majka S, McGuire PG, Das A. Regulation of matrix metalloproteinase expression by tumor necrosis factor in a murine model of retinal neovascularization. Invest Ophthalmol Vis Sci 2002; 43: 260-266.

[77] Jin M, He S, Worpel V, Ryan SJ, Hinton DR. Promotion of adhesion and migration of RPE cells to provisional extracellular matrices by TNF-alpha. IOVS 2000; 41: 4324-4332.

[78] Bevitt DJ, Mohamed J, Catterall JB, et al. Expression of ADAMTS Metalloproteinases in the Retinal Pigment Epithelium Derived Cell Line ARPE-19: Transcriptional Regulation by TNF $\alpha$.. Biochim Biophys Acta - Gene Structure and Expression 2003; 1626: 83-91.

[79] Das A, McGuire PG. Retinal and choroidal angiogenesis: pathophysiology and strategies for inhibition. Prog Retin Eye Res 2003; 22: 721-748.

[80] Hackett SF, Campochiaro PA. Modulation of plasminogen activator inhibitor-1 and urokinase in retinal pigmented epithelial cells. IOVS 1993; 34: 2055-2061.

[81] Kvanta A, Shen WY, Sarman S, et al. Matrix metalloproteinase (MMP) expression in experimental choroidal neovascularization. Curr Eye Res 2000; 21: 684-690. 
[82] Lambert V, Munaut C, Jost M, et al. Matrix metalloproteinase-9 contributes to choroidal neovascularization. Am J Pathol 2002; 161: 1247-1253.

[83] Lambert V, Wielockx B, Munaut C, et al. MMP-2 and MMP-9 synergize in promoting choroidal neovascularization. FASEB J 2003; 17: 2290-2292.

[84] Das A, McLamore A, Song W, et al. Retinal neovascularization is suppressed with a matrix metalloproteinase inhibitor. Arch Ophthalmol 1999; 117: 498-503.

[85] Berglin L, Sarman S, van der Ploeg I, et al. Reduced choroidal neovascular membrane formation in matrix metalloproteinase-2-deficient mice. IOVS 2003; 44: 403-408.

[86] Zeng R, Wen F, Zhang X, Su Y. Serum levels of matrix metalloproteinase 2 and matrix metalloproteinase 9 elevated in polypoidal choroidal vasculopathy but not in age-related macular degeneration. Mol Vis 2013; 19: 729-736.

[87] Chau KY, Sivaprasad S, Patel N, et al. Plasma levels of matrixmetalloproteinase-2 and -9 (MMP-2 and MMP9) in age-related macular degeneration. Eye 2008; 22: 855-859.

[88]Tatar O, Adam A, Shinoda K, et al.Matrix metalloproteinases in human choroidal neovascular membranes excised following verteporfin photodynamic therapy. Br J Ophthalmol. 2007; 91:1183-1189.

[89] Jonas JB, Jonas RA, Neumaier M, Findeisen P. Cytokine concentration in aqueous humor of eyes with diabetic macular edema. Retina 2012; 32: 2150-2157.

[90] Kwon J, Choi JA, Jee D. Matrix Metalloproteinase-1 and Matrix Metalloproteinase-9 in the Aqueous Humor of Diabetic Macular Edema Patients. PLoS One 2016; 11: e0159720.

[91] Wang F, Rendahl KG, Manning WC, Quiroz D, Coyne M, Miller SS. AAV-mediated expression of vascular endothelial growth factor induces choroidal neovascularization in rat. IOVS 2003; 44: 781-790.

[92] Witmer AN, Vrensen GF, Van Noorden CJ, Schlingemann RO. Vascular endothelial growth factors and angiogenesis in eye disease. Prog Retin Eye Res 2003; 22: 1-29.

[93] Lee S, Jilani SM, Nikolova GV, Carpizo D, Iruela-Arispe ML. Processing of VEGF-A by matrix metalloproteinases regulates bioavailability and vascular patterning in tumors. J Cell Biol 2005; 169: 681-691.

[94] Barbolina MV, Stack MSN. Membrane type 1-matrix metalloproteinase: substrate diversity in pericellular proteolysis. Semin Cell Dev Biol 2008; 1: 24-33.

[95] Itoh Y, Ito N, Nagase H, Evans RD, Bird SA, Seiki M. Cell surface collagenolysis requires homodimerization of the membrane-bound collagenase MT1-MMP. Mol Biol Cell 2006; 17: 5390-5399.

[96] Camodeca C, Cuffaro D, Nuti E, Rossello A. ADAM metalloproteinases as potential drug targets. Curr Med Chem 2018, 25: 1-26.

[97] Edwards DR, Handsley MM, Pennington CJ. The ADAM metalloproteinases. Mol Aspects of Med 2008; 29: 258-289.

[98] White JM. ADAMs: modulators of cell-cell and cell-matrix interactions. Curr Opin Cell Biol 2003; 15: 598606. 
[99] Yan X, Lin J, Rolfs A, Luo J. Differential expression of the ADAMs in developing chicken retina. Dev Growth Differ 2011; 53:726-739.

[100] Rossello A, Nuti E, Ferrini S, Fabbi M. Targeting ADAM17 Sheddase Activity in Cancer. Curr Drug Targets 2016; 17: 1908-1927.

[101] Maretzky T, Scholz F, Koten B, et al. ADAM10-mediated Ecadherin release is regulated by proinflammatory cytokines and modulates keratinocyte cohesion in eczematous dermatitis. J Invest Dermatol 2008; 128: 1737-1746.

[102] Kelwick R, Desanlis I, Wheeler GN, Edwards DR. The ADAMTS (A Disintegrin and Metalloproteinase with Thrombospondin motifs) family. Genome Biol 2015; 16: 113.

[103] Hollyfield GJ, Rayborn ME, Midura RJ, Shadrach KG, Acharya S. Chondroitin sulfate proteoglycan core proteins in the interphotoreceptor matrix: a comparative study using biochemical and immunohistochemical analysis. Exp Eye Res 1999; 69: 311-322.

[104] Colige A, Li SW, Sieron AL, Nusgens BV, Prockop DJ, Lapiere CM. cDNA cloning and expression of bovine procollagen I Nproteinase: a new member of the superfamily of zinc-metalloproteinases with binding sites for cells and other matrix components. Proc Nat Acad Sci 1997; 94: 2374-2379.

[105] Fernandes RJ, Hirohata S, Engle JM, et al. Procollagen II amino propeptide processing by ADAMTS-3Insights on dermatosparaxis, J Biol Chem 2001; 276: 31502-31509.

[106] Wang YS, Friedrichs U, Eichler W, Hoffmann S, Wiedemann P. Inhibitory effects of triamcinolone acetonide on bFGF-induced migration and tube formation in choroidal microvascular endothelial cells. Graefes Arch Clin Exp Ophthalmol 2002; 240: 42-48.

[107] Webb AH, Gao BT, Goldsmith ZK, et al. Inhibition of MMP-2 and MMP-9 decreases cellular migration, and angiogenesis in in vitro models of retinoblastoma. BMC Cancer 2017; 17: 434.

[108] Becerra M, Morescalchi E, Gandolfo F, et al. Clinical Evidence of Intravitreal Triamcinolone Acetonide in the Management of Age-Related Macular Degeneration. Curr Drug Targets 2011; 12: 149-172.

[109] Samtani S, Amaral J, Campos MM, et al. Doxycycline-mediated inhibition of choroidal neovascularization. Invest Ophthalmol Vis Sci 2009; 50: 5098-51006.

[110] Kim D, Ko H, Park GB, Hur D, Kim YS, Yang JW. Vandetanib and ADAM inhibitors synergistically attenuate the pathological migration of EBV-infected retinal pigment epithelial cells by regulating the VEGFmediated MAPK pathway. Experimental and Therapeutic Medicine 2017; 13: 1415-1425.

[111] Griffioen AW. AG-3340 (Agouron Pharmaceuticals Inc). IDrugs 2000; 33: 336-345.

[112] Bradey ME, Cheng L, Bartsh D-U, et al. Preventive Versus Treatment Effect of Ag3340, a Potent Matrix Metalloproteinase Inhibitor in a Rat Model of Choroidal Neovascularization. J Ocul Pharmacol Ther 2004; 20: 217-236.

[113] Kohri T, Moriwaki M, Nakajima M, et al. Reduction of experimental laser-induced choroidal neovascularization by orally administered BPHA, a selective metalloproteinase inhibitor. Graefe's Arch Clin Exp Ophthalmol 2003; 241: 943-952. 
[114] Das A, McLamore A, Song W, et al. Retinal neovascularization is suppressed with a matrix metalloproteinase inhibitor. Arch Ophthalmol 1999; 117: 498-503.

[115] Garcia CR, Bartsch DU, Rivero ME, et al. Efficacy of Prinomastat ${ }^{\circledR}$ (AG3340), a matrix metalloprotease inhibitor, in treatment of retinal neovascularization. Curr Eye Res 2002; 24: 33-38.

[116] Pasquale TR, Tan JS. Update on antimicrobial agents: new indications of older agents. Exp Opin Pharmacother 2005; 6: 1681-1691.

[117] Cox CA, Amaral J, Salloum R, et al. Doxycycline's effect on ocular angiogenesis: an in vivo analysis. Ophthalmology 2010; 117: 1782-1791.

[118] Su W, Li Z, Lin M, et al. The effect of doxycycline temperaturesensitive hydrogel on inhibiting the corneal neovascularization induced by BFGF in rats. Graefes Arch Clin Exp Ophthalmol 2011; 249: 421-427.

[119] Su W, Li Z, Li Y, et al. Doxycycline enhances the inhibitory effects of bevacizumab on corneal neovascularization and prevents its side effects. Invest Ophthalmol Vis Sci 2011; 52: 9108-9115.

[120] Su W, Li Z, Li F, Chen X, Wan Q, Liang D. Doxycycline-Mediated Inhibition of Corneal Angiogenesis: An MMP-Independent Mechanism. IOVS 2013; 54: 783-788.

[121] Garcia RA, Pantazatos DP, Gessner CR, Go KV, Woods VL Jr, Villarreal FJ. Molecular interactions between matrilysin and the matrix metalloproteinase inhibitor doxycycline investigated by deuterium exchange mass spectrometry. Mol Pharmacol 2005; 67: 1128-1136.

[122] Inoue K, Torimura T, Nakamura N, Sata M. Vandetanib, an Inhibitor of VEGF Receptor-2 and EGFReceptor, Suppresses Tumor Development and Improves Prognosis of Liver Cancer in Mice. Clin Cancer Res 2012; 18: 3924-3933.

[123] Bressler NM. Photodynamic therapy of subfoveal choroidal neovascularization in age-related macular degeneration with verteporfin: two-year results of 2 randomized clinical trials-tap report 2. Arch Ophthalmol 2001; 119:198-207.

[124] Verteporfin In Photodynamic Therapy Study Group. Verteporfin therapy of subfoveal choroidal neovascularization in age-related macular degeneration: two-year results of a randomized clinical trial including lesions with occult with no classic choroidal neovascularization--verteporfin in photodynamic therapy report 2 . Am J Ophthalmol 2001; 131: 541-560.

[125] Tatar O, Adam A, Shinoda K, et al. Matrix metalloproteinases in human choroidal neovascular membranes excised following verteporfin photodynamic therapy. J Ophthalmol 2007; 91: 1183-1189.

[126] Zhu WH, Guo X, Villaschi S, et al. Regulation of vascular growth and regression by matrix metalloproteinases in the rat aorta model of angiogenesis. Lab Invest 2000; 80: 545-555.

127 Zhang JJ, Sun Y, Hussain AA, Marshall J. Laser-mediated activation of human retinal pigment epithelial cells and concomitant release of matrix metalloproteinases. IOVS 2012; 53: 2928-2937. 